\title{
Best Bets for Accelerating Family Planning in Pakistan: The case for engaging family physicians and the for-profit private sector
}

Ashfaq Rehman

Anam Malkani

Follow this and additional works at: https://knowledgecommons.popcouncil.org/departments_sbsr-rh

Part of the Health Services Research Commons

How does access to this work benefit you? Let us know!

\section{Recommended Citation}

Rehman, Ashfaq and Anam Malkani. 2020. "Best Bets for Accelerating Family Planning in Pakistan: The case for engaging family physicians and the for-profit private sector," brief. Islamabad: Population Center Pakistan. 


\section{Best Bets for Accelerating Family Planning in Pakistan}

\section{The Case for Engaging Family Physicians and the For-Profit Private Sector}

\section{Total Market Approach and the For-Profit Private Sector: The International Evidence:}

Pakistan along with 150 other countries committed to the UN Sustainable Development Goals (SDGs). One of the requirements of these goals is ensuring universal access to sexual and reproductive healthcare services, including family planning, by 2030. To reach this goal, efforts must be escalated.

A Total Market Approach (TMA) is widely recognized as a means of strengthening family planning markets and expanding access and provision of services. It allows multiple sectors-public, non-profit, and for-profit private- to flourish, resulting in diversification, better allocation of resources, and long-term sustainability. There is a growing recognition that, while the public sector bears the ultimate responsibility for health, governments must better harness the potential of the private sector to widen access to health services.

Given the resource constraints of the public sector, the limited success of the non-profit private sector, and the untapped opportunity in the commercial private sector, TMA is a promising means to expand access to family planning (FP) services and improve contraceptive security and long-term sustainability. A TMA requires engagement of all sectors in the roles most suitable for them in FP service provision-for example, the public and the private non-profit sectors may cater to the poor and the low wealth quintiles, while the private commercial sector provides services to consumers who have greater ability to pay. ${ }^{2}$ This would allow growth of service provision in the for-profit private sector and better targeting of donor funds and government subsidies to those who need them most.

Where there is a risk of donor funds or government subsidies being phased out, a TMA allows for diversification of the market. ${ }^{3}$ This approach can expand overall FP coverage and is especially useful where a range of donor or public sector funded suppliers (such as social marketing programs and non-governmental organization [NGOs]) already exist in the market and may be displacing commercial players-such a situation results in misalignment of resources and lack of long-term sustainability, as even those consumers who have greater ability and willingness to pay may be taking advantage of subsidies. ${ }^{4}$ While the profit motive of the commercial private sector may not lend itself to widespread and equitable provision of health services, creative strategies and alternative business models can make the private sector's role compatible with public and donor interests. Financially profitable commercial models allow for sustainability and reduce the dependence on donors and changing political interests.

Given the large unmet demand, public sector delivery failures, and limited role of the private sector in the current landscape of FP service provision, there is a case for enabling the commercial private sector to play a more significant role. 
This would certainly not eliminate the need for the public sector and the non-commercial private sector, but it would enable all sectors to play more complementary roles in the family planning market. Expanding the commercial private sector will free up resources of the public sector to better target those who cannot pay commercial prices or to focus on demand generation. The non-profit sector can continue to be useful in serving the FP needs of the low-income clients who have some ability to pay. ${ }^{5}$

Evidence shows that many women in the developing world already rely on private sector providers for various types of illnesses, as well as for family planning services, due to ease of access, shorter waiting times, and a perception of better service. 5,6 Private physicians are also well-positioned to meet unmet demand for FP services owing to their ongoing relationships and rapport with their customers. ${ }^{7}$
Drug shops and pharmacies are also important private sector players in improving access to and providing basic information about contraceptive products. They are already an important source of advice and treatment for patients with a variety of minor ailments. Experiences from Bangladesh show that drug shops not only provide limited FP services but are often also the preferred option for clients seeking information and counseling. ${ }^{8}$

Use of pharmacies and shops is key where public sector facilities face frequent shortages and stock-outs of products. They are also good outlets for providing services to men who are less likely to visit clinics for family planning needs or for repeat purchase of temporary methods like condoms and pills. ${ }^{9}$ Training, quality assurance, and reliable supply of commodities are important in enabling this segment of the market.

Strategies to improve the quality and coverage of private sector health services can be classified as shown in Table 1. ${ }^{10,11}$

\begin{tabular}{|c|c|c|}
\hline \multirow{4}{*}{ Market-based } & Contracting & Purchasing services from the private sector \\
\hline & Financing & $\begin{array}{l}\text { Financial incentives such as grants, subsidies and tax } \\
\text { relief for private services and products }\end{array}$ \\
\hline & $\begin{array}{l}\text { Franchising and Social } \\
\text { Marketing }\end{array}$ & $\begin{array}{l}\text { Using commercial channels and communications } \\
\text { approaches to market networks of service providers } \\
\text { (franchises) or products (social marketing) }\end{array}$ \\
\hline & Collaborating & $\begin{array}{l}\text { Coordinating and creating alliances among private and } \\
\text { public sector actors }\end{array}$ \\
\hline \multirow{2}{*}{ Administrative } & Regulating & $\begin{array}{l}\text { Setting and enforcing standards for the } \\
\text { private sector }\end{array}$ \\
\hline & Training & Educating and supporting private sector providers \\
\hline Public Empowerment & Informing & $\begin{array}{l}\text { Educating consumers about healthy } \\
\text { behaviors and the role of the private sector }\end{array}$ \\
\hline
\end{tabular}

\section{A Review of TMA and Private Sector Approaches in Some Other Countries}

Although the term "Total Market Approach" (TMA) is relatively new, stakeholders have been using similar concepts to transition their programs off from public and donor subsidies for many years. TMA strategies have been used with priority health products such as condoms, contraceptives, oral rehydration salts, zinc, and insecticide-treated bed nets. In general, implementing a TMA program starts with conducting a Landscape Assessment or a Segmentation Analysis to better understand the market needs so resources can be targeted where they are needed. This leads to the development of a TMA plan and strategies for moving forward and strengthening, coordination, and advocacy among the various partners. It is generally the government that takes on the role of actively stewarding the process.
Experience from Mali, Uganda, and Kenya suggests that introducing a TMA framework strengthens stewardship of reproductive health (RH) / FP markets, most notably by generating data to help understand market strengths and weaknesses, and by forging improved multisectoral relationships that recognize the strategic role of the private sector. In Mali, a number of activities, such as generating intelligence through a Market Segmentation Study, establishing a TMA sub-committee led by the Directorate of Pharmacy and Medicine (DPM) under the Ministry of Health, and identification of pricing restrictions as a barrier for commercial brands, helped implement the TMA program. In Uganda, TMA implementation led to a strengthened role of the Ministry of Health in building coalitions and partner- 
ships and in understanding policies and regulations that are inhibiting increased access to $\mathrm{RH} / \mathrm{FP}$ products through the private sector. In Kenya, the Ministry of Health has made important progress in strengthening key stewardship functions for its RH/FP market. It has generated a substantial amount of intelligence through diagnostic studies, segmentation analysis, and quantification of the for-profit private sector role in the FP market; established a TMA working group that holds quarterly meetings; and allows private providers to access free FP commodities through public sector sourcing.

\section{Pakistan's Experience with Social Marketing and the Private Sector}

In Pakistan, Greenstar Social Marketing (GSM) was set up as an affiliate of Population Services International in 1991 with the primary objective of marketing FP products and services through private sector outlets. GSM implements what is known as the social franchise model, under which it provides contraceptive pills, intrauterine devices (IUD), injectables, condoms, and implants to clients through selected private sector clinics branded as Greenstar or Sabz Sitara, and knowledge and skill-based training to the clinic-based providers. GSM has trained 7,000 Sabz Sitara providers since its formation. In addition, under its social marketing program, GSM supplies its brands of combined oral contraceptive pills, emergency contraceptive pills, and condoms to over 30,000 pharmacies and medical shops, and condoms to over 70,000 retail shops across the country. GSM-marketed contraceptives are mostly received free of cost from donors and sold at various price points to earn revenues that help to recover the cost of operations. In the process, GSM also caters to customers from higher wealth quintiles who can pay commercial prices for brands from the for-profit private sector.

The Marie Stopes Pakistan (MSP) is a local NGO registered under the Societies Act, 1860. It provides a wide range of comprehensive $\mathrm{RH}$ and FP services through clinics located in 34 districts across Pakistan. MSP operates 32 static centers branded as Behtar Zindagi (Better Life) clinics in urban and peri-urban areas. In addition, it implements a social franchise model, branded as Suraj clinics, through a network of around 400 private sector practitioners across the country.
Many of its clinics offer free or subsidized services to the poor through a redeemable voucher scheme.

Between 1997 and 2007, the Futures Group, now Palladium, implemented a social marketing program in Pakistan known as Key Social Marketing (KSM) to expand the contraceptive market for private sector manufacturers and suppliers using the principles of the "Manufacturers Model."The Project was funded by the Department for International Development (DFID) until 2003, and then by the United States Agency for International Development (USAID) until it ended in 2007. It provided technical assistance to ZAFA, a local pharmaceutical partner, to improve the quality of its hormonal pills and injectables. KSM also provided marketing and communications support to increase sales of ZAFA's brands of contraceptives as well as the condom brands marketed by its local distribution partners.

The project helped create an enabling environment for the commercial private sector to grow in a market where the contraceptive prevalence rate (CPR) was stagnating and competition from donor-funded contraceptives was fierce. During its second phase, the project saved USAID over $\$ 3.5$ million in commodity cost by leveraging the resources of private sector partners.

The KSM experience demonstrated that, if given adequate support, the for-profit private sector in Pakistan can play a bigger role in the FP program by bringing in new users and creating a more sustainable market that is not dependent on donor commodity assistance. In 2006, full-priced condoms, pills, and injectables supported by KSM were used by over 430,000 couples who would otherwise have availed public sector or other subsidized sources.

The impact of social marketing programs would be far greater if their product subsidies were targeted at the less wealthy consumers who need them most, leaving the urban, better-off customers to be served by the commercial private sector. In addition, if IUDs and Injections could be sold to family physicians outside the franchised clinics supported by effective training programs, the payoff would be much higher in terms of increased CPR. Availability of provider dependent methods through private physicians would also attract more investment from pharmaceutical companies. 


\section{The Argument for Enabling the For-Profit Private Sector to Enhance Access to Family Planning in Pakistan in the Current Scenario}

According to the Pakistan Demographic and Health Survey (PDHS) 2017-18, the total demand for family planning, i.e., the percentage of married women of reproductive age who expressed a desire to either prevent or delay childbirth, is $51.5 \%$. However, only $34.2 \%$ are using any method of contraception, implying unmet need of over $17 \%$. Of the $34.2 \%$ using any method of contraception, the majority are using modern methods. The most common of the modern contraceptive methods are condoms, used by $9.2 \%$ of women, followed by female sterilization, used by $8.8 \%$. Use of IUDs and injectables is low ( $2.1 \%$ and $2.5 \%$ of women, respectively) while pills are used by only $1.7 \%$ of women. ${ }^{12}$

Table: 2 Contraceptive Prevalence Rate- Modern Method (excluding Lam and others)

\begin{tabular}{|l|l|l|}
\hline Contraceptive Method & $2017 / 2018$ & $2012 / 2013$ \\
\hline Condoms & $9.2 \%$ & $8.8 \%$ \\
\hline Female Sterilization & $8.8 \%$ & $8.7 \%$ \\
\hline Injectables & $2.5 \%$ & $2.8 \%$ \\
\hline IUD & $2.1 \%$ & $2.3 \%$ \\
\hline Pill & $1.7 \%$ & $1.6 \%$ \\
\hline Implant & $0.4 \%$ & - \\
\hline Male Sterilization & $0.1 \%$ & $0.3 \%$ \\
\hline Modern Method & $24.8 \%$ & $24.4 \%$ \\
\hline Any Method & $34.5 \%$ & $35.4 \%$ \\
\hline Unmet Need & $17.3 \%$ & $20.1 \%$ \\
\hline
\end{tabular}

Source: Pakistan Demographic and Health Survey (PDHS) 2017-2018 and 2012/2013

The most worrisome observation is that there has been no growth in the modern contraceptive prevalence rate $(\mathrm{mCPR})$ in the five years since the last PDHS was conducted (2012 $\neg-13)$. If we exclude implants, which were not captured in the 2012 $\neg-13$ survey, the overall $\mathrm{mCPR}$ (not including the lactational amenorrhea method and others) has remained the same at $24.4 \%$ during the period. Prevalence of injectables, IUD, and male sterilization-all provider dependent methodshas come down by $0.3,0.2$, and 0.2 percentage points respectively, while condom use has increased by 0.4 percentage points and prevalence of female sterilization and oral pills has remained almost unchanged. Pakistan has therefore fallen far short of its goal of achieving a 55\% CPR by 2020, as pledged at the 2012 London FP Summit, and the current CPR trend bodes ill for the SDG commitment to achieve universal access to RH/ FP services by 2030. In response to Suo Moto decision taken by the Supreme Court of Pakistan on The Alarming Population Growth Rate, the Council of Common Interest has decided upon eight major initiatives that need to be taken to stabilize our population growth rate. One of these requires all public and private health facilities be mandated to offer family planning services. Several demand-side and supply-side issues underlie
Pakistan's poor performance against contraceptive usage targets. The public sector lacks the capacity for universal family planning service delivery. Public sector facilities tend to be understaffed and lack sufficient resources. ${ }^{13}$ Service quality can be poor, due to low staff motivation, problems in training and supervision, and staff absenteeism. ${ }^{14}$

Over the years, private health facilities in Pakistan have increased their share of the healthcare market despite being more expensive. Unfortunately, many of these facilities do not offer family planning services at present.

Even so, Figure 1 below shows that in just five years, the private sector's share of modern contraceptive users has increased by almost 8 percentage points, while the share of the public sector has decreased. If this trend continues, the private sector could eventually attain a bigger share of the family planning market than the public sector 
Figure 1: Percent distribution of modern contraceptive method users by most recent source of method (currently married women of ages 15-49)

PDHS 2012-13 PDHS 2017-18

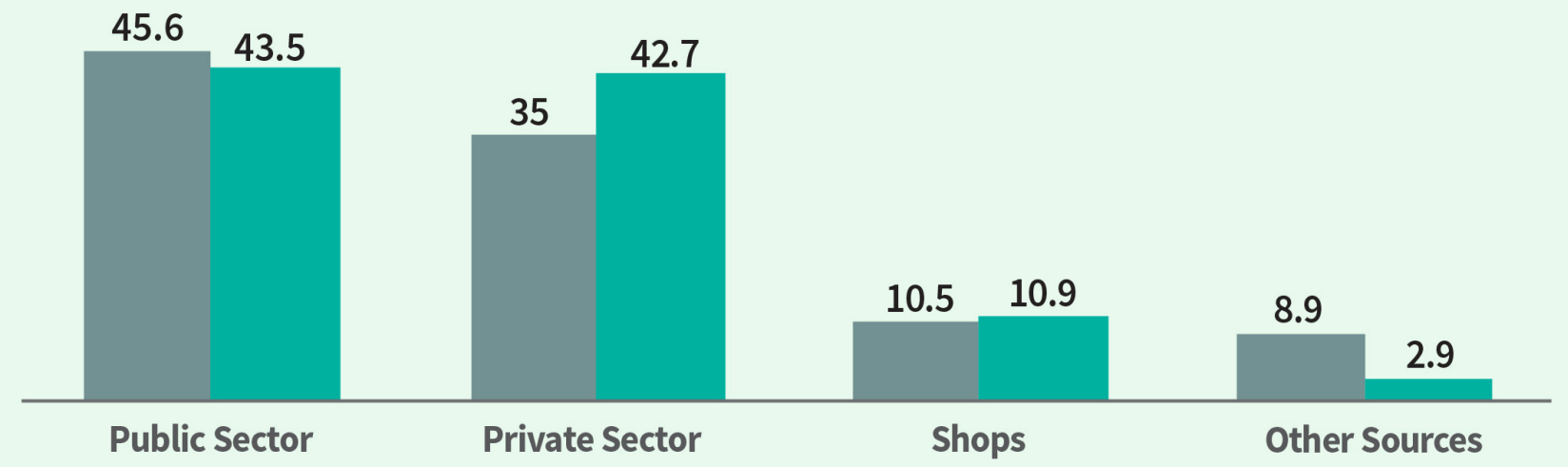

Source: Pakistan Demographic and Health Survey (PDHS) 2017-2018

Note: Private sector source includes providers, pharmacies, medical stores, and shops

\section{Sources of Modern Contraceptive Methods within the Private Sector}

IAmong the private sector FP users in Pakistan, 37.6 percent obtain contraceptives from a pharmacy or medical store, 27.7 percent from a hospital or clinic, 20.4 percent from shops, 12.5 percent from a private doctor, and $1.7 \%$ from a dispenser, or other sources (PDHS 2017-18). The share of users obtaining contraceptives from "pharmacies" and "private doctors" has increased rapidly in just five years, mainly due to the rise in the use of condoms, while the proportion of those obtaining services from private hospitals and clinics has decreased (Figure 2). This indicates that mainstreaming family physicians in the provision of FP service could play a huge role in uplifting the CPR in Pakistan.

PDHS 2012-13 PDHS 2017-18

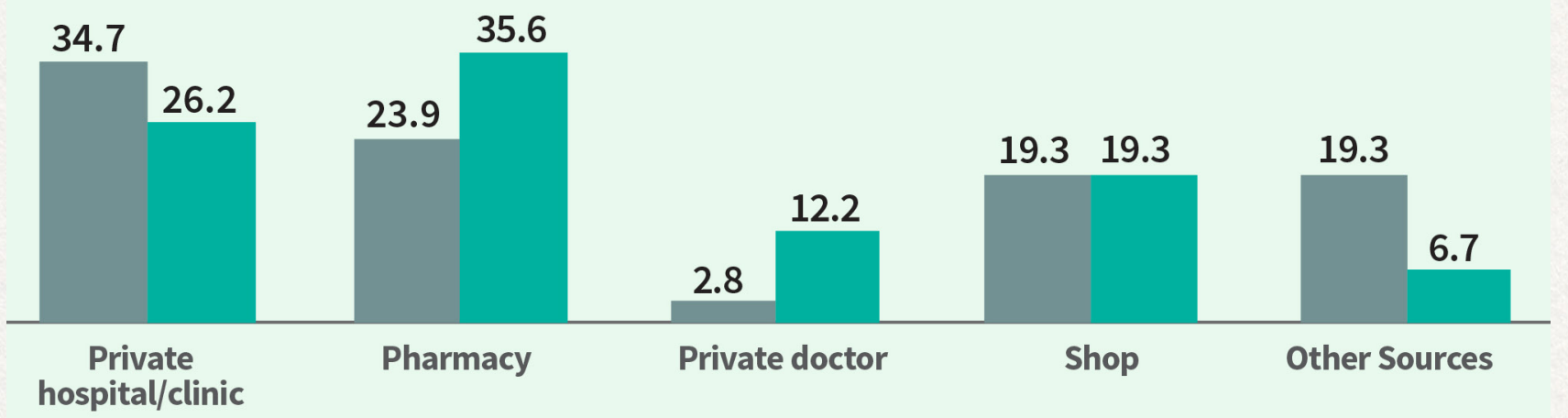

Source: Pakistan Demographic and Health Survey (PDHS) 2017-2018

In Pakistan, patients state several reasons for preferring to avail health services from the private sector rather than the public sector, including a cleaner environment, more client-centered attitudes of private providers, and better quality of contraceptive products. Private sector facilities are more numerous and easily accessible compared to public sector facilities, but only 41 percent of private sector providers in urban areas and 29 percent in rural areas are providing family planning services. ${ }^{15}$ While pharmacies perform better in terms of availability of family planning products, the methods they provide are limited to condoms, oral pills and emergency contraceptive pills only. 


\section{Private Sector Operators}

The private sector can be divided into for-profit commercial and non-profit non-commercial (NGOs, social franchises, and social marketing organizations). The non-commercial private sector has been working in Pakistan for many years but has not yet succeeded in significantly expanding access to and uptake of family planning services. This sector is primarily supported by donor agencies or by government subsidies - it is not financially sustainable, and evidence suggests that it may be crowding out the commercial private sector. ${ }^{17}$

Social franchises have attracted considerable interest as a means of improving the quality and expanding the impact of private sector health care provision. ${ }^{18}$ This model provides a way to leverage the existing health infrastructure by enabling and organizing private sector providers to expand access to family planning services. A study in Pakistan found that social franchise facilities did increase women's knowledge of modern methods of contraception and their preference for long-acting methods. ${ }^{19}$
However, Pakistan's GSM experience of social franchising also yields other important lessons. While social franchising allowed for a scale-up of service delivery, serious issues have been raised about monitoring and ability of the network to grow without ensuring a sustainable flow of commodities through donor assistance. ${ }^{20}$

A recent review found the evidence base for non-commercial or commercial private sector models to be weak, with a need for more data and evidence, and a stronger conceptual basis for linking outcomes with delivery models. ${ }^{21}$ Another study focused on Pakistan found insufficient evidence to suggest that the social marketing and social franchising models contributed to narrowing disparities in access to family planning: improvements in financial and geographical access were small. ${ }^{22}$ There is also a lack of evidence to suggest that these programs are effective in serving the poor population or achieving financial stability. ${ }^{23}$

Table 3: Social franchising and social marketing programs in Pakistan

\begin{tabular}{|l|l|l|}
\hline Organizations & Service and Products & Projects \\
\hline Greenstar Social Marketing & $\begin{array}{l}\text { Condoms, Injectables } \\
\text { ECP, IUD, Implants }\end{array}$ & $\begin{array}{l}\text { - Pabz Sitara clinics; } 7,000 \text { franchised providers } \\
\text { - Community-based workers - Baji } \\
\text { - Condoms through pharmacies and stores }\end{array}$ \\
\hline Marie Stopes Society & $\begin{array}{l}\text { Condoms, Injectables, } \\
\text { ECP, IUD, Implant, female } \\
\text { and male sterilization, } \\
\text { abortions }\end{array}$ & $\begin{array}{l}\text { - Behtar Zindagi centers (clinics) } \\
\text { - Suraj social franchise network of LHVs } \\
\text { Demand Side financing through vouchers } \\
\text { Roshni mobile outreach vans, which also provide } \\
\text { IUCD, FP counseling, and general medicine }\end{array}$ \\
\hline DKT International & $\begin{array}{l}\text { Condoms, Oral Pills, } \\
\text { ECP, Injections, IUD }\end{array}$ & $\begin{array}{l}\text { Dhanak program is being implemented in rural } \\
\text { areas using community midwives (CMWs) as key } \\
\text { service providers. FP products and promotional } \\
\text { material are provided to the service providers }\end{array}$ \\
\hline
\end{tabular}

Despite the limitations of the public and nonprofit sectors in fully meeting demand for family planning in Pakistan, for-profit private sector has not yet been enabled to provide these services at scale. Meanwhile, contraceptive prevalence remains chronically low, despite persistence of a high level of unmet need. A serious gap in service coverage prevails in most parts of the country, urban and rural, primarily owing to a semi-functional public health sector, sub-optimal provision in the private sector, and ineffective demand creation strategies. In this context, the for-profit sector offers a vast untapped potential for increasing access to services while achieving better targeting of subsidized resources.

In this paper, we focus on family physicians - a large segment of health service providers-as one of the Best Bet to expand FP use in the country mainly because of the following advantages:

- Very large in number; can significantly increase access to FP services across Pakistan

- MBBS doctors and therefore well qualified and trusted by patients

- Best suited to expand use of hormonal methods whose CPR has been stagnating

- Male providers can motivate husbands and offer non-invasive hormonal methods

- Already have linkages with the Pharmaceutical 
We find that this avenue is financially feasible and is well placed to increase uptake of contraception. Midwife clinics and female doctor clinics play a significant role in FP services provision, but male doctors are conspicuously absent.

Private sector players face several challenges in providing FP services. The most frequently cited issues point to a lack of demand among patients. Providers find that patients hold myths and misconceptions about contraception and fear of side effects is a significant barrier.
On the supply side, which is the most critical constraint to expansion of services through the private sector, availability of contraceptives, effective training programs, and lack of female staff in facilities are the most significant barriers. Service providers request public sector support in ensuring contraceptive supply and providing training. Interviews with pharmacists lead to similar findings, with demand-side issues including lack of demand for contraceptives and supply-side issues including lack of knowledge about contraceptives amongst pharmacy staff. ${ }^{24}$

\section{The Case for Provision of Family Planning Services through Family Physicians Supplied by Pharmaceutical Companies}

While social franchising and social marketing have a strong footprint in Pakistan, and pharmacies have served as a channel to buy condoms and pills, there has not yet been a concerted effort to enable other private sector players such as family physicians to provide family planning services in a sustainable, for-profit model. This is a significant opportunity-thus far, missed-to leverage the existing health infrastructure to scale family planning services and at the same time improve maternal and child health (MCH) outcomes in Pakistan. A combination of the strategies identified in Table 1 must be used to unlock the potential of the for-profit private channel, including collaborating, regulating, training, and informing. Key steps would include: (a) appropriate selection of providers; (b) training and workshops to educate on the health benefits of FP and birth spacing, relative advantages and disadvantages of each method, and management of side effects; (c) bringing selective pharmaceutical companies on board to recognize family physicians as a channel for their contraceptive products and ensure regular supply of contraceptives; and (d) formulating an advocacy plan to create an enabling regulatory environment for the companies and service providers.

\section{Perspective of Family Physicians}

Given the penetration of family physicians across the country-they are prevalent in rural and urban areas and often the first point of delivery for healthcare services-there is a case to be made for leveraging them in the provision of family planning. The potential efficacy of this channel is increased by the fact that $70 \%$ of family physicians in Pakistan are male. As such they can provide counseling and detailed information about FP to male household members, fulfilling a longstanding need in the country to directly engage men in family planning." Table 3 below gives a snapshot of the Strengths, Weaknesses, Opportunities and Threats(SWOT) of engaging the family physicians that have been derived largely from discussions with the members of family physicians association, other prominent providers, representatives from the pharmaceutical companies and other observations.

\section{STRENGTHS}

- Large number (over 100,000 estimated)

- Male providers can encourage inter-spousal discussion and offer non-invasive methods such as pills, injectables, and implants

- Family physicians have an elevated status in their communities as trusted health providers

- They are already qualified as MBBS doctors

- Leverage large existing patients' base to scale FP

- Reduce discontinuation rates through proper counseling and helping client select the most appropriate method

- MBBS training makes them already qualified to take on FP and provide follow-up services

- Already have linkages with pharmaceutical companies

- Can create alliances with Obstetrics and Gynecological Society of Pakistan (OGSP) and other associations for credibility and training opportunities

\section{WEAKNESSES}

- Lack adequate knowledge of FP products and services

- Male family physicians do not currently recognize FP as a male domain

- Providers have very busy practices and may not want to spend extra time to motivate clients to use FP products or services

- May be crowded out by the public sector

- Too much paper-based reporting can be a strong disincentive

- Possible penetration of low-priced subsidized contraceptives can demotivate partners

- Poor selection of providers can increase risk of complications and damage reputation

- Lack of demand creation activities and mass media support may discourage both physicians and pharmaceutical partners 
In interviews conducted by the second author in Lahore, family physicians shared that they have not been approached by the government to provide FP services. According to them -

1. Lack of awareness and contraceptive knowledge is the primary reason many providers are not currently offering FP services

2. They felt the government has not shown enough commitment to FP. The public sector should raise awareness among the general population and should equip and train the physicians.

3. They mentioned that although pharmaceutical companies proactively market other drugs, they do not approach physicians with contraceptives, nor do they educate them about these products. One of the respondents explained that one pharmaceutical company conducted several workshops for their brand of inhalers but has never mentioned any family planning products.

The major benefits to family physicians for providing FP services include increase in income through consultation fees and charges for procedures, as well as expansion of clientele in the form of men and women who visit them for FP services and avail other services as well.

The physicians felt that they would not be able to spend much time with each patient to proactively educate them on family planning. Those who already provide FP services only do so for patients who ask for them. They therefore suggested that they be provided marketing materials (pamphlets and posters) to keep in their waiting rooms, and community mobilization support if possible.

Effective enabling of family physicians will therefore require, at the minimum, their training, a regular supply of long-acting contraceptives, promotional support, and preferably also subsidies for customers who cannot pay the full price.

\section{Perspective of Pharmaceutical Companies}

Unlocking family physicians as a channel for provision of FP services requires creating effective links between them and pharmaceutical companies. Without a reliable, predictable, and affordable supply of contraceptives, regular promotional support, and updated information, family physicians will fail to deliver on the expected outcomes.

The availability of contraceptives currently marketed by pharmaceutical companies in Pakistan is limited to four major players, namely ZAFA pharmaceuticals, Aspen
Pharma, Bayer Pharmaceuticals, and Mass Pharma. Both ZAFA and Mass Pharma manufacture combined and emergency contraceptive pills. In addition, ZAFA also produces the 3-month DMPA (depot-medroxyprogesterone acetate) injectables. Bayer Pharma provides the Jadelle brand of contraceptive implants to the provincial government of Sindh and has other contraceptive products available in the retail markets.

The overall market size for pills is small as they constitute less than $2 \%$ of the total CPR. However, many of the oral pill brands are imported and earn a good margin on sales. In comparison, there are many more brands of condoms available through pharmacies and shops, which is understandable since condoms are the most popular contraceptive method. Other than the Sathi and Touch brands of condoms from Greenstar, which are donated, all other condom brands are commercially imported by local companies. There is no commercial availability of IUD or implants in Pakistan.

In interviews, representatives of pharmaceutical companies pointed to the following major barriers and constraints in supplying contraceptives to family physicians:

1. Family physicians are mostly male, and women will not come to them for FP services.

2. However, many believe that male physicians can insert implants and administer Injectables to their female clients since there are no privacy issues with these methods.

3. Regulatory issues are a significant barrier to pharmaceutical companies in marketing and selling contraceptive products to family physicians.

4. Mass media advertisements for hormonal contraceptive products are restricted, affecting demand creation for contraceptive brands.

5. The Drug Registration Authority (DRAP) is not clear about which drugs fall in which categories.

6. It is difficult for commercial companies to compete with socially marketed pill and condom brands, which have low prices and enjoy large-scale promotional support.

7. Most contraceptive products are imported, and pharmaceutical companies face challenges in finalizing their prices, especially when there is currency fluctuation.

The representatives believed that, if the option was available, most pharmaceutical companies would be willing to purchase contraceptives from the Ministry of Health and preferably sell them in their own brand names. They would also welcome marketing and regulatory support. 


\section{The Business Case}

It is important to consider the financial benefits of providing FP services through family physicians along with the potential impact on contraceptive prevalence and sustainability in Pakistan. Ultimate success will be achieved when the commercial sector is able to secure its own commodities, but this will require long-term planning and initial investment. The business case assumes that health departments at the federal or provincial level including Health Care Commissions will make provider-dependent methods, i.e., IUDs, implants, and injectables, available to family physicians through pharmaceutical partners, and will also finance other key aspects of support, such as training of physicians and medical representatives, market research, and demand generation activities. Since the government will sell the contraceptives, the commodity cost will be recoverable. We also assume that $\mathrm{MOH}$ will play a key facilitating role through its work with a "TMA Working Group," proposed in the next section.

In addition, the calculations are based on the following hypothetical assumptions to measure potential benefits.

- The potential customer base for family physicians and pharmaceutical partners lies in the highest, fourth, and middle wealth quintiles as they are currently not availing FP services despite need, and could pay commercial prices (Table 4)

Table 4: Unmet need for family planning in Pakistan, by wealth quintile

\begin{tabular}{|l|l|l|l|}
\hline Wealth quintile & $\begin{array}{l}\text { Unmet need for FP, } \\
\text { \% of CMWRA }\end{array}$ & $\begin{array}{l}\text { Estimated number of } \\
\text { CMWRA }\end{array}$ & $\begin{array}{l}\text { Estimated no. of CMWRA with } \\
\text { unmet need }\end{array}$ \\
\hline Lowest & 22.5 & $6,800,000$ & $1,530,000$ \\
\hline Second & 19.2 & $6,800,000$ & $1,305,600$ \\
\hline Middle & 17.5 & $6,800,000$ & $1,190,000$ \\
\hline Fourth & 14.5 & $6,800,000$ & 986,000 \\
\hline Highest & 13.7 & $6,800,000$ & 931,600 \\
\hline Total & 17.3 & $34,000,000$ & 5.9 million \\
\hline
\end{tabular}

- The average physician's consultation fees are estimated at PKR 250.00

- The number of family physicians trained and providing FP services is 5,000 in Year 1 of the program and an additional 5,000 in Year 2

- A provider serves 10 women/month for 10 months, adjusting for Ramadan and other holidays.

Based on these assumptions we arrive at the following potential impact:

- The number of women with unmet need from the highest to the middle quintiles served in Year 1 will be 100 (10/month x 10 months). The total number of women served will be 500,000 (100 x 5000 providers) or $16 \%$ of all women with unmet need from the three quintiles $(5,000 / 3,107,000)$, and 8.5\% of all women with unmet need $(500,000 / 5,900,000)$.

- At PKR 250 per client, each physician could potentially earn PKR 25,000 in year 1 from consultation fees alone by providing FP services (100 women x PKR 250 per visit).

- Assuming an average of around PKR 500 per client for insertion or administration charges for IUD, implant, or injections inclusive of any product margin, this could potentially add another PKR 50,000 per year in addition to the consultation fee.

- In Year 2, if a provider serves an additional 100 new FP patients, it will double the number of clients served, reduce the unmet need and increase her earnings by another PKR 25,000 in consultation fees over and above the insertion and administration charges. A mix of first time and repeat visits from previous year would exponentially increase her/his total earnings

- Estimates based on current training and awareness building cost of the Population Welfare Departments (PWD) in all provinces, and 5\% of the total cost of the PWDs as oversight cost, the total annual cost to the public sector for supporting this initiative will be PKR 876,943,834. Of this 5\% will be expended on training cost, $77 \%$ on creation and implementation of the oversight mechanism, and $18 \%$ on demand creation programs. These costs are rough estimations and a more realistic costing exercise must be taken if this initiative moves forward. 
The projections above would vary considerably depending on the assumptions such as a change in the number of family physicians that can be trained, number of women with unmet need that can be served by a physician in a given time period, change in demand etc.

The family physicians will only be trained in providing clinical and hormonal methods. They will not offer pills, condoms or emergency contraceptive pills but only prescribe or advise them to their clients as appropriate. This will stop cannibalization and lead to an increase in sales from private sector pharmacies and shops. It will also contribute to a more favorable image of family physicians as providers of more specialized FP services only.

Experience in many developing countries shows that for-profit private sector physicians are not only motivated by financial return but also want to be recognized for their contribution to a bigger cause. They constantly seek avenues to gain knowledge and new skills through regular training and other learning opportunities. Therefore, non-financial motivational aspects must be built into any plan.

\section{The Total Market Approach Working Group (TMAWG)}

We propose that a Total Market Approach Working Group (TMAWG) be set up to initiate the process of inducting private sector family physicians, supported by selected pharmaceutical concerns, in family planning service provision. The Group could be led by the $\mathrm{MOH}$ at the federal level or the Department of Health at the provincial level, and include representatives of the Family Physicians Association, pharmaceutical partners...as necessary.

The TMAWG would be responsible for steering the initiative and its core functions could include, among others, selection and training of participating private physicians and pharmaceutical concerns; facilitation of health authorities in contraceptive procurement; facilitation of appropriate contraceptive pricing policies; coordination of partners' marketing plans; commissioning of demand creation and necessary research activities; and progress monitoring. 


\section{References}

1. World Health Organization, 2000. The world health report 2000 - Health systems: improving performance. Geneva: World Health Organization; 2000.

2. Barnes, Jeffrey, Janet Vail, and Dawn Crosby. 2012. Total Market Initiatives for Reproductive Health. Bethesda, MD: Strengthening Health Outcomes through the Private Sector Project, Abt Associates.

3. Cisek, Cindi R., Kate Klein, Sayaka Koseki, and Rob Wood. Strengthening family planning stewardship with a total market approach: Mali, Uganda, and Kenya experiences. Public Administration and Development, 39 , no. 1 (2019): 47-56.

4. Brady, C., Weeden, L., Hutchings, J., Parks, J. 2016. Planning Guide for a Total Market Approach to Increase Access to Family Planning. Module 1: Landscape Assessment. Seattle, WA: PATH and Washington, DC: The Population Council, Evidence Project.

5. Smith E, Brugha R, Zwi A. 2001. Working with private sector providers for better health care, an introductory guide. London: Options E London School of Hygiene and Tropical Medicine.

6. Montagu DD, Anglemyer A, Tiwari M, Drasser K, Rutherford GW, Horvath T, Kennedy GE, Bero L, Shah N, Kinlaw HS. 2011. Private versus public strategies for health service provision for improving health outcomes in resource-limited settings. San Francisco, CA: Global Health Sciences, University of California, San Francisco

7. Abdel-Tawab, N., Oraby, D. and Bellows, B. 2016. Situational Analysis of the Private Sector in the Delivery of Family Planning Services in Egypt: Current Status and Potential for Increased Involvement. Research Report. The Evidence Project. Washington, DC: Population Council.

8. Khan TU, Malarcher S, Ahmed S, Sarker S, Arevalo M. The Blue Star Program: expanding access to injectable contraception through private sector outlets in Bangladesh. Unpublished draft; 2012.

9. High-Impact Practices in Family Planning (HIP). Drug Shops and Pharmacies: Sources for family planning commodities and information. Washington, DC: USAID; 2013 Jun.

10. Waters H, Hatt L, Peters D. 2003. Working with the private sector for child health. Health Policy E Planning 18: 127-37.

11. Peters DH, Mirchandani GG, and Hansen PM. 2004. Strategies for engaging the private sector in sexual and reproductive health: how effective are they? Department of International Health, Johns Hopkins University Bloomberg School of Public Health, Baltimore, MD, USA. Health Policy Plan19: i5-i21.

12. National Institute of Population Studies and ICF. 2019. Pakistan Demographic and Health Survey 2017-18. Islamabad, Pakistan, and Rockville, Maryland, USA: NIPS and ICF.

13. Population Council, 2019. Public-Private Partnership to Accelerate Family Planning Uptake in Pakistan: A Conceptual Framezork. Population Council, Islamabad.

14. McBride J, Ahmed R. Social Franchising as a Strategy for Expanding Access to Reproductive Health Services; 2001

15. Population Council, 2019. Private Sector Stakeholder Analysis. Population Council, Islamabad.

16. Population Council. 2016. Landscape Analysis of Family Planning in Pakistan. Report and Brief. Population Council, Islamabad.

17. Ibid

18. Bishai D, Shah N, Walker D, Brieger W, Peters D. 2008. Social franchising to improve quality and access in private health care in developing countries. Harvard Health Policy Review 9: 184-97.

19. Hennink M, Clements S. 2005. The impact of franchised family planning clinics in poor urban areas of Pakistan. Stud Fam Plann. 2005;36(1):33-44. doi: https://doi. org/10.1111/j.1728-4465.2005.00039.x

20. McBride, J. and Ahmed, R., 2001. Social franchising as a strategy for expanding access to reproductive health services: A case study of the Greenstar Service Delivery Network in Pakistan.

21. Montagu D, Goodman C, Berman P, Penn A, Visconti A. Recent trends in working with the private sector to improve basic healthcare: a review of evidence and interventions. Health Policy Plan. 2016

22. Gheorghe, A., Zaman, R.U., Scott, M. and Witter, S., 2018. Delivering reproductive health services through non-state providers in Pakistan: understanding the value for money of different approaches. Global health research and policy, 3(1), p.33.

23. Samad, N., Madichie, N.O. and Nwankwo, S., 2008. The role of social marketing models in family health interventions in Pakistan. The Marketing Review, 8(1), pp.61-74.

24. Population Council. 2019. Improving Access to Family Planning Services through the Private Sector in Pakistan: A Stakeholder Analysis. Population Council, Islamabad.

25. Based on conversations with the Islamabad Vice President of Pakistan Academy of Family Physicians 